\title{
Leadership aspirations among residents in obstetrics and gynecology in the United States: a cross-sectional analysis
}

\author{
Brindha Bavan ${ }^{1 *}$ (D), Jordan Chavez ${ }^{2}$, Briana Saravanabavanandhan ${ }^{1}$, Jie Li $^{3}$ and Shannon MacLaughlan David ${ }^{4}$
}

\begin{abstract}
Background: Most residents and faculty in obstetrics and gynecology (Ob/Gyn) are women. However, only a third of Ob/Gyn academic leadership positions are held by women in the United States.

Methods: This is an IRB-approved cross-sectional study of leadership aspirations among Ob/Gyn residents in the U.S. as related to gender and mentorship using an electronic survey distributed nationwide in 2017. The primary outcome was resident interest in academic leadership. Mediator variables included demographics and training environment characteristics. Descriptive statistics and comparative analyses were performed using SPSS.

Results: We received 202 completed surveys, for a representative cross-section of $4 \%$ of all Ob/Gyn residents in the U.S. The majority (86\%) of respondents were women $(n=174)$, reflecting the same gender distribution of all $\mathrm{Ob} / \mathrm{Gyn}$ residents in training. Sixty-seven percent of all respondents reported an interest in pursuing academic leadership $(n=133)$. Women reported leadership aspirations less often than men $(64 \%$ vs $86 \%, p<0.05)$ and reported lower mean Likert scores (3.73 vs $4.14, p<0.05)$ regarding interest in leadership. A marginal difference between mean Likert scores was observed between women and men when controlled for other demographics (coefficient -0.344 , SE 0.186; $p=0.066$ ). No difference in leadership aspirations was noted between women and men when controlled for mentorship, presence of female program director, and presence of three or more female leaders in a program.
\end{abstract}

Conclusions: Gender disparity in goal-setting toward leadership is identified as early as residency training in Ob/ Gyn. This imbalance in leadership aspirations can be addressed with targeted mentorship.

Keywords: Leadership, Obstetrics, Gynecology, Residents, Gender, Mentorship, Graduate medical education

\section{Background}

Women comprise about half of most graduating medical school classes in the United States, and now represent the majority of all students currently in medical school. However, women are still underrepresented in academic medicine, comprising only about a third of faculty $[1,2]$. Furthermore, leadership positions such as chair, vice chair, and division director are disproportionately held by men. Even in the field of obstetrics and gynecology (Ob/Gyn), in which $85 \%$ of residents in the U.S. are

\footnotetext{
* Correspondence: brindhas@stanford.edu

${ }^{1}$ Department of Obstetrics and Gynecology, Stanford University School of Medicine, 300 Pasteur Drive, Stanford, CA 94305-5317, USA

Full list of author information is available at the end of the article
}

female, only $21-35 \%$ of departmental academic leadership positions are held by women $[1,3]$.

Many possible explanations exist for this discrepancy. Gender biases and disparities have been measured in resident evaluations, faculty promotions, career development initiatives, and compensation [4-12]. However, there are no studies in the contemporary literature reporting on gender disparities among leadership aspirations of residents in Ob/Gyn in the U.S.

The purpose of this study is to evaluate the percentage of $\mathrm{Ob} / \mathrm{Gyn}$ residents in the U.S. who identify academic leadership as a personal goal. We hypothesized that fewer women than men identify leadership as a goal during residency, and that women who do aspire to leadership are more likely to have had specific mentorship

(c) The Author(s). 2019 Open Access This article is distributed under the terms of the Creative Commons Attribution 4.0 International License (http://creativecommons.org/licenses/by/4.0/), which permits unrestricted use, distribution, and 
addressing leadership and have seen leadership modeled among women in their department.

\section{Methods}

This cross-sectional study of academic leadership aspirations among Ob/Gyn residents in the U.S. was approved by the Stanford School of Medicine Institutional Review Board and was conducted using an electronic survey tool developed by our study team (see Additional file 1). The survey was distributed in 2017 to the U.S. Ob/Gyn Residency Program Coordinator Group ListServ, which was assembled and is maintained through the Association of Professors in Gynecology and Obstetrics. Residency program coordinators were asked to distribute the survey to their respective residents, who were incentivized to complete the survey by a chance to win one of five \$100 Amazon gift cards. Survey data were collected over a period of 6 weeks and managed using the secure web application Research Electronic Data Capture (REDCap) hosted at Stanford University [13].

The primary outcome for this study was identification of leadership as a goal during residency. Respondents were asked to agree or disagree on a Likert scale $(1=$ strongly disagree, $2=$ disagree, $3=$ neutral, $4=$ agree, and $5=$ strongly agree) with the following statement: "It is a goal of mine to someday hold a leadership position (e.g. program director, department chair, society president)." The primary outcome was defined as an answer of agree or strongly agree for categorical descriptive analysis. Mean Likert scores were used for regression analyses.

Mediator variables included demographics (age, postgraduate year, relationship status, number of children) and current training environment (mentorship exposure and gender distribution within residency class, faculty, and academic leaders). It is important to note that responses to survey questions related to program environment are self-perceived by respondents and were not confirmed as factual data.

Descriptive and comparative (chi-square, T-test, F-test, and multivariate linear regression) analyses were performed using SPSS. A $p$-value of $<0.05$ was designated as significant.

\section{Results}

The survey was distributed to 241 residency program coordinators for dissemination to trainees. We received 202 completed surveys from residents across the U.S., representing 4\% of the estimated $5187 \mathrm{Ob} /$ Gyn residents in training at the time of the survey. The demographics of our cross-section is similar to what is known about the population of $\mathrm{Ob} / \mathrm{Gyn}$ residents in general in the U.S. Specifically, the majority of respondents were women $(86 \%, n=174)$, the distribution of training years was even, and the majority of respondents were from university $(71 \%, n=143)$ or university-affiliated $(16 \%$, $n=32)$ programs [14].

All demographic characteristics are listed in Table 1.

Sixty-seven percent of respondents $(n=133)$ identified leadership as a goal. Women were less likely than men to identify interest in leadership both when comparing total percentage $(64 \%$ vs $86 \%, p<0.05)$ and mean Likert scale responses (3.73 vs $4.14, p<0.05)$. This gender disparity in responses persisted with marginal statistical significance $(p=0.066)$ after controlling for the effect of other demographic variables in a multivariate linear regression model (Table 2).

About half of respondents reported receiving specific mentorship regarding leadership (Table 3). Sixty percent of participants had a mentor who was an academic leader him/herself. A majority of residents were from programs with mostly female trainees and mostly female or half female/half male faculty. Most residents who answered the survey had a female program director and clerkship director, but the minority of department chair

Table 1 Demographic characteristics of survey respondents

\begin{tabular}{|c|c|}
\hline Characteristic & n (\%) \\
\hline \multicolumn{2}{|l|}{ Gender } \\
\hline Women & $174(86)$ \\
\hline Men & $28(14)$ \\
\hline \multicolumn{2}{|l|}{ Age (years) } \\
\hline $25-29$ & $108(53)$ \\
\hline $30-34$ & $86(43)$ \\
\hline $35-40$ & $8(4)$ \\
\hline \multicolumn{2}{|l|}{ Post-graduate Year } \\
\hline PGY-1 & $36(18)$ \\
\hline PGY-2 & $64(32)$ \\
\hline PGY-3 & $49(24)$ \\
\hline PGY-4 & $51(25)$ \\
\hline PGY-5+ & $2(1)$ \\
\hline \multicolumn{2}{|l|}{ Residency Setting } \\
\hline University & $143(71)$ \\
\hline University-affiliate & $32(16)$ \\
\hline Community & $27(13)$ \\
\hline \multicolumn{2}{|l|}{ Relationship Status } \\
\hline Single & $65(32)$ \\
\hline Married/Domestic Partnership & $113(56)$ \\
\hline Other & $23(11.5)$ \\
\hline Divorced/Separated & $1(0.5)$ \\
\hline \multicolumn{2}{|l|}{ Children } \\
\hline Yes & $34(17)$ \\
\hline No & $168(83)$ \\
\hline
\end{tabular}


Table 2 Multivariate linear regression model of academic leadership interest by demographic characteristics

\begin{tabular}{|c|c|c|c|}
\hline Characteristic & Unadjusted Mean & Coefficient \pm SE & $P$-value \\
\hline \multicolumn{4}{|l|}{ Gender } \\
\hline Female & 3.73 & $-0.344 \pm 0.186$ & \multirow[t]{2}{*}{$p=0.66$ (marginal) } \\
\hline Male & 4.14 & - & \\
\hline \multicolumn{4}{|l|}{ Age } \\
\hline $25-29$ & 3.76 & $-0.407 \pm 0.351$ & \multirow[t]{3}{*}{$p>0.1$} \\
\hline $30-34$ & 3.80 & $0.248 \pm 0.342$ & \\
\hline $35+$ & 4.00 & - & \\
\hline \multicolumn{4}{|l|}{ Post-graduate Year } \\
\hline PGY-1 and PGY-2 & 3.88 & $-0.237 \pm 0.146$ & \multirow[t]{2}{*}{$p>0.05$} \\
\hline PGY-3 and PGY-4 & 3.69 & - & \\
\hline \multicolumn{4}{|l|}{ Residency Setting } \\
\hline University/university-affiliate & 4.10 & $0.652 \pm 0.188$ & \multirow[t]{2}{*}{$p<0.05$} \\
\hline Other & 3.45 & - & \\
\hline \multicolumn{4}{|l|}{ Relationship Status } \\
\hline Married/domestic partnership & 3.66 & $-0.060 \pm 0.209$ & \multirow[t]{3}{*}{$p>0.1$} \\
\hline Single & 4.03 & $0.204 \pm 0.217$ & \\
\hline Divorced/Other & 3.71 & - & \\
\hline \multicolumn{4}{|l|}{ Children } \\
\hline Yes & 3.68 & $-0.072 \pm 0.196$ & \multirow[t]{2}{*}{$p>0.1$} \\
\hline No & 3.81 & - & \\
\hline Constant & - & $3.361 \pm 0.398$ & $p<0.05$ \\
\hline
\end{tabular}

SE Standard Error

Statistically significant values in bold

positions were held by women, and only about a third of trainees reported their respective program having a total of three or more female academic leaders.

Four training environment factors correlated with a statistically significant increase in leadership interest (Table 4), including receiving direct mentorship about leadership $(p<0.01)$, having a mentor who is a leader him/herself $(p<0.01)$, having a female program director $(p<0.01)$, and having three or more academic leaders who are women in the department $(p<0.05)$.

In a multivariate linear regression model including all demographic and significant training environment characteristics, the effect of gender on interest in academic leadership weakened $(p=0.09)$. Training at a university or university-affiliate setting $(p<0.01)$ and receiving targeted mentorship about leadership $(p<0.05)$ remained statistically significant when controlling for all other factors (Table 5). Interestingly, only $46.4 \%$ of women $(n=79)$ reported being mentored regarding leadership, compared to $57.1 \%$ of men $(n=16)(p<0.05)$.

Respondents were asked to agree or disagree with statements that may influence interest in pursuing leadership (Table 6). Over three-fourths of respondents cited personal career development $(n=151,75 \%)$, the opportunity to mentor colleagues/trainees $(n=161$,
$80 \%$ ), and the chance to positively impact the profession of Ob/Gyn at large $(n=173,86 \%)$ as motivating factors for interest in academic leadership. Less than a third were incentivized by increased monetary compensation $(n=54,27 \%)$. Additionally, one-third were concerned about interference with work/life balance $(n=66,32 \%)$ and distraction from clinical practice $(n=67,33 \%)$ as limiting factors. Of note, while targeted mentorship regarding leadership was a strongly associated factor in multivariate linear regression modeling, less than half of respondents $(n=99,49 \%)$ agreed that receiving mentorship would motivate them to pursue leadership.

\section{Discussion}

We report that interest in leadership among Ob/Gyn residents correlates with trainees' gender, training in a university or university-affiliate program, access to mentorship, and presence of female role models in leadership positions. A marginal gender disparity persists when controlled for other demographic characteristics of respondents, but this gender gap is closed when analysis is controlled for the effect of mentorship and presence of female role models. While this could be explained by an effect too small for detection in our study, it is also 
Table 3 Characteristics of current training environment

\begin{tabular}{ll}
\hline Characteristic & $\mathrm{n}(\%)$ \\
\hline Mentorship encouraging leadership & $99(49)$ \\
Yes & $103(51)$ \\
Mentor who is a leader him/herself & \\
Yes & $121(60)$ \\
No & $81(40)$ \\
Residency Makeup & \\
Mostly to entirely women & $199(98.5)$ \\
$50 / 50$ & $3(1.5)$ \\
Mostly to entirely men & $0(0)$ \\
Faculty Makeup & \\
Mostly to entirely women & $90(44.5)$ \\
$50 / 50$ & $106(52.5)$ \\
Mostly to entirely men & $6(3)$ \\
Female Department Chair & \\
Yes & $80(40.5)$ \\
No & $118(59.5)$ \\
Female Program Director & $66(33)$ \\
Yes & $62(30)$ \\
No & \\
Female Clerkship Director & $121(60)$ \\
\hline & \\
\hline & \\
Notal number of female leaders & \\
\hline
\end{tabular}

*F-test completed for this analysis

likely that mentorship and role modeling can negate the effects of gender bias in career development.

Our findings are congruent with other studies that have demonstrated gender disparities in academic leadership, promotion, and salaries. Significant gender differences in salary persist among faculty physicians in the U.S., even accounting for age, experience, markers of productivity, and academic rank [8, 15]. Additionally, women are less likely to attain senior level positions than male counterparts, even after adjusting for publicationrelated productivity [16]. This effect persists in the field of Ob/Gyn, in which women predominate the population of faculty, and yet the majority of leaders are male $[1,3,17]$. In a cross-sectional study of 950 academic medicine departments, Hofler et al. showed that $\mathrm{Ob} /$ Gyn departments had more women in leadership than other specialties in 2013. However, when considering
Table 4 Effect of current training environment characteristics on academic leadership interest

\begin{tabular}{|c|c|c|}
\hline Characteristic & Likert Mean & $P$-value ${ }^{*}$ \\
\hline \multicolumn{3}{|c|}{ Mentorship encouraging leadership } \\
\hline Yes & 4.11 & \multirow[t]{2}{*}{$p<0.01$} \\
\hline No & 3.48 & \\
\hline \multicolumn{3}{|c|}{ Mentor who is a leader him/herself } \\
\hline Yes & 3.92 & \multirow[t]{2}{*}{$p<0.01$} \\
\hline No & 3.59 & \\
\hline \multicolumn{3}{|l|}{ Residency makeup } \\
\hline Mostly to entirely women & 3.89 & \multirow[t]{3}{*}{$p>0.1$} \\
\hline $50 / 50$ & 4.33 & \\
\hline Mostly to entirely men & - & \\
\hline \multicolumn{3}{|l|}{ Faculty makeup } \\
\hline Mostly to entirely women & 3.80 & \multirow[t]{3}{*}{$p>0.1$} \\
\hline $50 / 50$ & 3.78 & \\
\hline Mostly to entirely men & 3.80 & \\
\hline \multicolumn{3}{|l|}{ Female Department Chair } \\
\hline Yes & 3.95 & \multirow[t]{2}{*}{$p>0.1$} \\
\hline No & 3.67 & \\
\hline \multicolumn{3}{|l|}{ Female Program Director } \\
\hline Yes & 3.93 & \multirow[t]{2}{*}{$p<0.01$} \\
\hline No & 3.57 & \\
\hline \multicolumn{3}{|l|}{ Female Clerkship Director } \\
\hline Yes & 3.88 & \multirow[t]{2}{*}{$p>0.1$} \\
\hline No & 3.56 & \\
\hline \multicolumn{3}{|l|}{ Total number of female leaders } \\
\hline 0 & 3.60 & \multirow[t]{4}{*}{$p<0.05$} \\
\hline 1 & 3.52 & \\
\hline 2 & 3.76 & \\
\hline $3+$ & 4.10 & \\
\hline
\end{tabular}

the ratio of leaders to the number of women in the field, women in $\mathrm{Ob} / \mathrm{Gyn}$ continue to be underrepresented at the leadership level compared to other specialties [1]. Our results suggest that a contributing factor to these disparities is that men identify leadership as a specific goal more often while in training, and therefore, initiate a targeted career development path sooner than women.

Our study also suggests that mentorship and female role modeling in leadership can address this gender gap. Studies in other fields have found that academic departments led by female department chairs were more likely to hire and promote female physicians and program directors through mentorship [18]. Mentorship has also been shown to influence career decision-making in $\mathrm{Ob} /$ Gyn. Cain et al. reported that $43 \%$ of female residents perceived that men were mentored and recruited more 
Table 5 Multivariate linear regression model of academic leadership interest by all factors

\begin{tabular}{|c|c|c|c|}
\hline Factor & $\begin{array}{l}\text { Unadjusted } \\
\text { Mean }\end{array}$ & Coefficient \pm SE & $P$-value \\
\hline \multicolumn{4}{|l|}{ Gender } \\
\hline Female & 3.73 & $-0.312 \pm 0.181$ & $p=0.09$ \\
\hline Male & 4.14 & - & \\
\hline \multicolumn{4}{|l|}{ Age } \\
\hline $25-29$ & 3.76 & $-0.311 \pm 0.339$ & $p>0.1$ \\
\hline $30-34$ & 3.80 & $0.183 \pm 0.330$ & \\
\hline $35+$ & 4.00 & - & \\
\hline \multicolumn{4}{|l|}{ Post-graduate Year } \\
\hline$P G Y-1$ and $P G Y-2$ & 3.88 & $0.280 \pm 0.139$ & $p>0.1$ \\
\hline PGY-3 and PGY-4 & 3.69 & - & \\
\hline \multicolumn{4}{|l|}{ Residency Setting } \\
\hline University/university-affiliate & 4.10 & $0.417 \pm 0.198$ & $p<0.05$ \\
\hline Other & 3.45 & - & \\
\hline \multicolumn{4}{|l|}{ Relationship Status } \\
\hline $\begin{array}{l}\text { Married/domestic } \\
\text { partnership }\end{array}$ & 3.66 & $0.050 \pm 0.199$ & $p>0.1$ \\
\hline Single & 4.03 & $0.338 \pm 0.207$ & \\
\hline Divorced/Other & 3.71 & - & \\
\hline \multicolumn{4}{|l|}{ Children } \\
\hline Yes & 3.68 & $-0.090 \pm 0.186$ & $p>0.1$ \\
\hline No & 3.81 & & \\
\hline \multicolumn{4}{|c|}{ Mentorship encouraging leadership } \\
\hline Yes & 4.11 & $0.505 \pm 0.128$ & $p<0.01$ \\
\hline No & 3.48 & - & \\
\hline \multicolumn{4}{|c|}{ Mentor who is a leader him/herself } \\
\hline Yes & 3.92 & $0.195 \pm 0.130$ & $p>0.1$ \\
\hline No & 3.59 & - & \\
\hline \multicolumn{4}{|l|}{ Female Program Director } \\
\hline Yes & 3.93 & $0.120 \pm 0.194$ & $p>0.1$ \\
\hline No & 3.57 & - & \\
\hline \multicolumn{4}{|l|}{ Total number of female leaders } \\
\hline 0 & 3.60 & - & $p>0.1$ \\
\hline 1 & 3.52 & - & \\
\hline 2 & 3.76 & - & \\
\hline $3+$ & 4.10 & $0.071 \pm 0.089$ & \\
\hline Constant & - & $3.361 \pm 0.398$ & $p<0.05$ \\
\hline
\end{tabular}

SE Standard Error

Statistically significant values in bold

than women for faculty positions [19]. We note in our study that $46 \%$ of women reported they had received mentorship regarding leadership, compared to $57 \%$ of men, suggesting the presence of gender bias among mentors $(p<0.05)$.
We cannot assess presence of gender bias in faculty, staff, or other colleagues of our respondents with our survey tool. However, gender bias in resident evaluations and other assessments in career development and advancement is well documented [7, 11, 12, 20, 21]. A recent qualitative analysis of attending physician evaluations of residents in emergency medicine suggested that assertive characteristics were judged differently between men and women [11]. Similarly, among junior residents in $\mathrm{Ob} / \mathrm{Gyn}$, women received harsher feedback from labor and delivery nurses than men [7]. We suggest that this intrinsic bias in evaluators may influence leadership aspirations among women and may contribute to disparities observed or perceived in mentorship.

Addressing explicit and implicit gender biases with targeted interventions can reduce gender gaps in evaluation and promotion. For example, the University of California, Davis School of Medicine initiated training of search committees and promotion panels in unconscious bias and made significant progress in promoting women. The University of Massachusetts Medical School has increased the number of female full professors through mentoring and awards programs to support career development for women [22]. Increasing the number of professors and leaders who are women will improve trainees' exposure to female role models, which was found to be a significant contributor to leadership aspirations in our study.

We are cautious in drawing conclusions from a crosssectional study, as survey-based methodology cannot demonstrate causality and comes with intrinsic biases. Here we opted for a method of distribution of our survey that included all programs in the U.S., thereby, eliminating the selection bias associated with inviting "representative" programs for participation. This is a strength of our study. However, our method of distribution coupled with its anonymity does not allow us to measure a true survey response rate or describe non-responders. While our cohort of respondents is only $4 \%$ of the entire population of $\mathrm{Ob} / \mathrm{Gyn}$ residents in the U.S., we believe it reflects a representative cross-section of the population we are studying, as demonstrated by the matching characteristics noted in demographics (e.g., gender distribution).

Given the introductory nature of this work, we intentionally kept our survey brief. We did not collect data on racial/ethnic background, a known contributor to perceptions and experiences in career development $[19,23,24]$. While we queried objective characteristics of training environments (e.g., university/university-affiliate versus community program), we did not ask about perceptions of the workplace environment, which is known to influence women in their career trajectories $[10,23-25]$. We anticipate including these important 
Table 6 Perceptions of Academic Leadership that Influence Interest

\begin{tabular}{|c|c|c|c|}
\hline Factor & Agree n (\%) & Neutral n (\%) & Disagree $\mathrm{n}(\%)$ \\
\hline \multicolumn{4}{|l|}{ Motivating } \\
\hline Focused mentorship about leadership & $99(4)$ & $45(22)$ & $58(29)$ \\
\hline Positive examples of leaders within faculty & $121(60)$ & $26(13)$ & $55(27)$ \\
\hline Personal career development & $151(75)$ & $36(18)$ & $15(7)$ \\
\hline Prestige & $60(29.5)$ & $61(30.5)$ & $81(40)$ \\
\hline Opportunity to mentor colleagues/trainees & $161(80)$ & $14(7)$ & $7(3)$ \\
\hline Chance to impact profession of OB/GYN & $173(86)$ & $23(11.5)$ & $5(2.5)$ \\
\hline Increase in total monetary compensation & $54(27)$ & $94(46)$ & $54(27)$ \\
\hline \multicolumn{4}{|l|}{ Limiting } \\
\hline Concern for interference with work/life balance & $66(32)$ & $70(34)$ & $66(32)$ \\
\hline Distraction from clinical practice & $67(33)$ & $76(37)$ & $65(32)$ \\
\hline Too much of a time commitment & $59(29)$ & $78(39)$ & $65(32)$ \\
\hline
\end{tabular}

mediator variables in a survey distributed directly to residents and fellows in training.

\section{Conclusions}

To our knowledge, this is the first cross-sectional analysis of current Ob/Gyn residents in the U.S. and their aspirations toward leadership. By evaluating correlations here, we can consider causal relationships between existing systems in training programs and gender equality in academic medical leadership. We identified gender disparity in leadership goal setting as early as residency training. The effect of targeted mentorship, presence of female role models in leadership, and implementation of education around unconscious bias in residency curricula should be further explored in follow up research studies as avenues for overcoming barriers for women and men alike.

\section{Additional file}

Additional file 1: Survey Questionnaire. (PDF $56 \mathrm{~kb}$ )

\section{Abbreviations}

Ob/Gyn: Obstetrics and gynecology; REDCap: Research Electronic Data Capture

\section{Acknowledgments}

Kate Shaw, MD MS (Residency Program Director) and Jackie Signor (Residency Program Coordinator) for assistance with distribution of the survey tool.

\section{Authors' contributions}

BB - Literature review, research design, data analysis, manuscript writing. JC - Literature review, research design, manuscript writing. BS - Data analysis, manuscript writing. $J \mathrm{~L}$ - Data analysis. SMD - Literature review, research design, data analysis, manuscript writing. All authors have read and approved this edition of the manuscript.

\section{Authors' information}

BB - Clinical Fellow. JC - Oncology Licensed Clinical Social Worker. BS - Clinical Researcher. JL - Graduate Medical Education Program Manager, Education Specialist, Statistician. SMD - Associate Professor of Clinical Obstetrics \&
Gynecology as well as Division Director of Gynecologic Oncology at University of Chicago Illinois.

\section{Funding}

This study used Research Electronic Data Capture (REDCap), which received research information technology grant support (Stanford Clinical and Translational Science Award Number UL1TR001085 from NIH/NCRR). This funding body did not play a role in the design of the study, data collection, data analysis/interpretation, or manuscript writing. Otherwise, there was no external funding for this project.

\section{Availability of data and materials}

The datasets used and/or analyzed during the current study are available from the corresponding author on reasonable request.

\section{Ethics approval and consent to participate}

Stanford IRB-approved study (protocol \#38947).

Respondents were provided an electronic consent form attached to the email invitation to partake in the survey study detailing risks, benefits, and alternatives of participating and clicked either "I agree to participate" or "I do not agree to participate."

Consent for publication

Not applicable.

\section{Competing interests}

The authors declare that they have no competing interests.

\section{Author details}

'Department of Obstetrics and Gynecology, Stanford University School of Medicine, 300 Pasteur Drive, Stanford, CA 94305-5317, USA. Stanford Health Care, Department of Social Work, 300 Pasteur Drive, Stanford, CA 94305-5617, USA. ${ }^{3}$ Department of Graduate Medical Education, Stanford University School of Medicine, 300 Pasteur Drive - Room HC435, Stanford, CA 94305-5207, USA ${ }^{4}$ Department of Obstetrics and Gynecology, University of Illinois at Chicago, 1740 W Taylor St, Chicago, IL 60612, USA.

Received: 28 December 2018 Accepted: 19 August 2019

Published online: 04 September 2019

\section{References}

1. Hofler LG, Hacker MR, Dodge LE, Schutzberg R, Ricciotti HA. Comparison of women in department leadership in obstetrics and gynecology with those in other specialties. Obstet Gynecol. 2016;127(3):442-7.

2. Ricciotti HA, Dodge LE, Aluko A, Hofler LG, Hacker MR. Geographic comparison of women in academic obstetrics and gynecology departmentbased leadership roles. Obstet Gynecol. 2017;130(4):853-61. 
3. Baecher-Lind L. Women in leadership positions within obstetrics and gynecology: does the past explain the present? Obstet Gynecol. 2012;120(6):1415-8.

4. Leonard JC, Ellsbury KE. Gender and interest in academic careers among first- and third-year residents. Acad Med. 1996;71(5):502-4.

5. Ly DP, Seabury SA, Jena AB. Differences in incomes of physicians in the United States by race and sex: observational study. BMJ. 2016;353:i2923.

6. Helitzer DL, Newbill SL, Cardinali G, Morahan PS, Chang S, Magrane D. Changing the culture of academic medicine: critical mass or critical actors? J Women's Health (Larchmt). 2017;26(5):540-8.

7. Galvin SL, Parlier AB, Martino E, Scott KR, Buys E. Gender Bias in nurse evaluations of residents in obstetrics and gynecology. Obstet Gynecol. 2015;126(Suppl 4):7S-12S.

8. Jena $A B$, Olenski $A R$, Blumenthal DM. Sex differences in physician salary in US public medical schools. JAMA Intern Med. 2016;176(9):1294-304.

9. McLean MR, Morahan PS, Dannels SA, McDade SA. Geographic mobility advances careers: study of the executive leadership in academic medicine (ELAM) program for women. Acad Med. 2013;88(11):1700-6.

10. Pololi LH, Civian JT, Brennan RT, Dottolo AL, Krupat E. Experiencing the culture of academic medicine: gender matters, a national study. J Gen Intern Med. 2013;28(2):201-7.

11. Mueller AS, Jenkins TM, Osborne M, Dayal A, O'Connor DM, Arora VM Gender differences in attending Physicians' feedback to residents: a qualitative analysis. J Grad Med Educ. 2017;9(5):577-85.

12. Carnes M, Bartels CM, Kaatz A, Kolehmainen C. Why is John more likely to become department chair than Jennifer? Trans Am Clin Climatol Assoc. 2015;126:197-214.

13. Harris PA, Taylor R, Thielke R, Payne J, Gonzalez N, Conde JG. Research electronic data capture (REDCap)--a metadata-driven methodology and workflow process for providing translational research informatics support. J Biomed Inform. 2009;42(2):377-81.

14. National Resident Matching Program, Results and Data: 2017 Main Residency Match (R). Washington, D.C.: National Resident Matching Program; 2017.

15. Freund KM, Raj A, Kaplan SE, Terrin N, Breeze JL, Urech TH, et al. Inequities in academic compensation by gender: a follow-up to the National Faculty Survey Cohort Study. Acad Med. 2016;91(8):1068-73.

16. Carr PL, Raj A, Kaplan SE, Terrin N, Breeze JL, Freund KM. Gender differences in academic medicine: retention, rank, and leadership comparisons from the National Faculty Survey. Acad Med. 2018.

17. Hofler L, Hacker MR, Dodge LE, Ricciotti HA. Subspecialty and gender of obstetrics and gynecology faculty in department-based leadership roles Obstet Gynecol. 2015;125(2):471-6.

18. Cheng D, Promes S, Clem K, Shah A, Pietrobon R. Chairperson and faculty gender in academic emergency medicine departments. Acad Emerg Med. 2006;13(8):904-6.

19. Cain JM, Schulkin J, Parisi V, Power ML, Holzman GB, Williams S. Effects of perceptions and mentorship on pursuing a career in academic medicine in obstetrics and gynecology. Acad Med. 2001;76(6):628-34.

20. Caffrey L, Wyatt D, Fudge N, Mattingley H, Williamson C, McKevitt C. Gender equity programmes in academic medicine: a realist evaluation approach to Athena SWAN processes. BMJ Open. 2016;6(9):e012090.

21. Girod S, Fassiotto M, Grewal D, Ku MC, Sriram N, Nosek BA, et al. Reducing implicit gender leadership Bias in academic medicine with an educational intervention. Acad Med. 2016;91(8):1143-50.

22. VD DML, Raezer CL, Sloane RA. The state of women in academic medicine: the pipeline and pathways to leadership. Washington, D.C.: Association of American Medical Colleges; 2014.

23. Pololi $\mathrm{LH}$, Jones $\mathrm{SJ}$. Women faculty: an analysis of their experiences in academic medicine and their coping strategies. Gend Med. 2010;7(5):438-50.

24. Pololi LH, Krupat E, Civian JT, Ash AS, Brennan RT. Why are a quarter of faculty considering leaving academic medicine? A study of their perceptions of institutional culture and intentions to leave at 26 representative U. S medical schools Acad Med. 2012;87(7):859-69.

25. Westring AF, Speck RM, Sammel MD, Scott P, Tuton LW, Grisso JA, et al. A culture conducive to women's academic success: development of a measure. Acad Med. 2012;87(11):1622-31.

\section{Publisher's Note}

Springer Nature remains neutral with regard to jurisdictional claims in published maps and institutional affiliations.

\section{Ready to submit your research? Choose BMC and benefit from:}

- fast, convenient online submission

- thorough peer review by experienced researchers in your field

- rapid publication on acceptance

- support for research data, including large and complex data types

- gold Open Access which fosters wider collaboration and increased citations

- maximum visibility for your research: over $100 \mathrm{M}$ website views per year

At $\mathrm{BMC}$, research is always in progress.

Learn more biomedcentral.com/submissions 